\title{
Rechtsprechung
}

\section{Darlegungs- und Beweislast bei Ersitzung}

OLG Nürnberg Urteil vom 06.09.2017 - 12 U 2086/15

\section{Amtliche Leitsätze:}

1. Wer sich darauf beruft, Eigentum an einer beweglichen Sache durch Ersitzung gem. §937 Abs. 1 BGB erlangt zu haben, trägt die Darlegungs- und Beweislast für seinen zehnjährigen Eigenbesitz. (Rn. 73)

2. Die Beweislast für mangelnden guten Glauben bei Besitzerwerb oder für spätere Bösgläubigkeit trägt hingegen, wer die Ersitzung bestreitet und gegen den Ersitzenden Ansprüche aus Eigentum an der Sache geltend machen will. Allerdings trifft denjenigen, der sich auf Ersitzung beruft, eine sekundäre Darlegungslast hinsichtlich seiner Gutgläubigkeit für Erwerbsvorgänge in seiner Sphäre. (Rn. 92 und 93)

3. Diese Beweislastverteilung gilt auch, wenn eine Sache dem früheren Besitzer gestohlen wurde oder sonst abhandengekommen ist (entgegen OLG Celle, Urt. v. 17.9.2010 - 4 U 30/08, GRUR-RR 2011, 24). (Rn. 95-97).

\section{Vorinstanz:}

LG Ansbach, Endurteil vom 11.9.2015 - 20 891/14

\section{Tenor}

- I. Die Berufung des Klägers und Widerbeklagten gegen das Endurteil des LG Ansbach vom 11.9.2015 (Az. 2 O 891/14) wird zurückgewiesen.

II. Der Kläger und Widerbeklagte trägt die Kosten des Berufungsverfahrens.

III. Das Urteil ist vorläufig vollstreckbar. Das Endurteil des LG Ansbach vom 11.9.2015 (Az. 20 891/14) ist ohne Sicherheitsleistung vorläufig vollstreckbar.

Der Kläger kann die Vollstreckung des Beklagten durch Sicherheitsleistung in Höhe von $110 \%$ des jeweils vollstreckbaren Betrages abwenden, wenn nicht der Beklagte vor der Vollstreckung Sicherheit in Höhe von $110 \%$ des jeweils zu vollstreckenden Betrags leistet.

\section{Beschluss}

Der Streitwert wird für das Berufungsverfahren auf 100.000,00 EUR festgesetzt.

\section{Entscheidungsgründe}

[1] A. Die Parteien streiten mit Klage und Widerklage um die Freigabe zweier von der Polizei beim Beklagten am 1.10.2009 sichergestellter (Anlage K6) und in der Folge von der Staatsanwaltschaft beim AG Ansbach hinterlegter (Anlage K16) Gemälde.
[2] 1. Der Kläger ist Enkel des am ... 1966 verstorbenen Malers H. P. Der Beklagte ist Autoteile-Großhändler, weist weder eine akademische Ausbildung (im Kunstbereich oder in anderen Sparten) auf noch ist er kunstbeflissen, künstlerisch tätig oder an Kunstgeschichte interessiert.

[3] Die sichergestellten Gemälde waren vor ihrer Sicherstellung durch die Polizei zunächst im Privathaus des Beklagten in Haundorf und anschließend in Büroräumen im Betrieb Gunzenhausen des Beklagten aufgehängt; später wurden sie dort abgehängt und in einem Schrank im oberen Stockwerk des Betriebsgebäudes verwahrt.

[4] Im Juni 2009 trat die Tochter des Beklagten, die Zeugin K. $\mathrm{H}$., mit einem Auktionshaus in Luzern/Schweiz in Kontakt, um die Möglichkeit der Veräußerung eines der Bilder im Rahmen einer Auktion auszuloten (E-Mail-Verkehr Anlagen K7, K8). Am 2.7.2009 erfolgte eine Besichtigung der Gemälde durch einen Mitarbeiter des Auktionshauses im Betrieb des Beklagten in Gunzenhausen. In der Folge wurde wegen des Verdachts der Hehlerei der - als gestohlen gemeldeten - Bilder ein Ermittlungsverfahren der Staatsanwaltschaft Ansbach gegen den Beklagten eingeleitet, in dessen Rahmen die Bilder sichergestellt wurden. Dieses Verfahren (Staatsanwaltschaft Ansbach $1114 \mathrm{Js}$ 8347/09) endete mit einer Einstellung gem. § 170 Abs. 2 StPO.

[5] 2. Nach Vortrag des Klägers soll es sich bei diesen Gemälden um die 1924 bzw. 1939 entstandenen Werke "X" und "Y-1" bzW. "Y-2" des Malers H. P. handeln, die einen Wert von über 100.000 EUR aufweisen würden. Diese Gemälde habe H. P. seiner Tochter C. S., geb. P. - der Mutter des Klägers - geschenkt; nach deren Tod am 12.9.1993 und dem Tod deren Ehemanns Prof. Dr. jur. F. S. am 25.2.1996 sei das Eigentum an den Bildern im Wege der Erbfolge auf den Kläger sowie dessen Schwester $C$. 
B., geb. S., übergegangen (Anlagenkonvolut K15). Frau B. habe ihre Ansprüche mit Vereinbarung vom 14.8.2010/16.8.2010 (Anlage K1) an den Kläger abgetreten.

[6] Die Originalgemälde seien - neben weiteren Bildern am 18.11.1986 bei einem Einbruch unbekannter Täter in das Anwesen der Eltern des Klägers in Stuttgart, H.-K.-Straße ..., entwendet worden. Wegen dieses Diebstahls seien polizeiliche Ermittlungen eingeleitet worden (Anlage K4); die beiden Bilder wurden unter Abbildung derselben im „BKA - Bundeskriminalblatt" in einer entsprechenden Kunstdatenbank der Polizei als gestohlen ausgeschrieben.

[7] Der Beklagte, bei dem die Bilder aufgefunden worden seien, habe hieran kein Eigentum erworben.

[8] 3. Der Beklagte trägt vor, er habe die sichergestellten Gemälde mutmaßlich 1986/1987 von seinem - 1993 verstorbenen - Stiefvater J. S. geschenkt bekommen. Herr S. habe dabei geäuBert, die Bilder von einem Antiquitätenhändler oder -sammler in Dinkelsbühl erworben zu haben.

[9] Die vom Kläger behauptete Provenienz der Gemälde und die daraus hergeleitete Aktivlegitimation des Klägers werde mit Nichtwissen bestritten. Insbesondere würden die behauptete Schenkung der Bilder seitens H. P.fe an dessen Tochter C. S., geb. P., sowie die behauptete Erbfolge bestritten, weiterhin, dass die betreffenden Bilder tatsächlich gestohlen worden seien. Schließlich werde die Echtheit der beim Beklagten sichergestellten Gemälde als Werke des Malers H. P. - trotz entsprechender Signierung der Bilder - bestritten; es sei nicht geklärt, ob es sich bei den beim Beklagten aufgefundenen Bildern tatsächlich um die behauptet gestohlenen Bilder handele und ob es sich hierbei um Originale, Kopien oder Fälschungen handele.

[10] Von dem behaupteten hohen Wert der Gemälde habe der Beklagte keine Kenntnis gehabt. Eigentum hieran habe der Beklagte schon aufgrund der Schenkung, jedenfalls aber infolge Ersitzung, erworben, nachdem er die Bilder viele Jahre besessen habe.

[11] Die Dauer des Besitzes des Beklagten wie auch dessen Gut- bzw. Bösgläubigkeit hinsichtlich deren vom Kläger behaupteter Herkunft ist zwischen den Parteien streitig.

[12] 4. Hinsichtlich des Sachverhalts und des jeweiligen Sachvorbringens wird ergänzend auf die tatsächlichen Feststellungen im angefochtenen Urteil Bezug genommen ( $\$ 540$ Abs. 1 S. 1 Nr. 1 ZPO).

[13] Der Kläger hat erstinstanzlich die Verurteilung des Beklagten zur Bewilligung der Freigabe der beiden hinterlegten Bilder begehrt. Der Beklagte hat als Widerkläger - unter der prozessualen Bedingung „für den Fall, dass die Klage abgewiesen wird" - die Verurteilung des Widerbeklagten zur Bewilligung der Freigabe der beiden hinterlegten Bilder begehrt.
[14] Das LG Ansbach hat nach Beweisaufnahme (Vernehmung der Zeugen K. R., J. S., K. H., M. H. und M. H.; Beiziehung der staatsanwaltschaftlichen Ermittlungsakten) mit Endurteil vom 11.9.2015 die Klage abgewiesen und der Widerklage stattgegeben, da der Beklagte Eigentum an den sichergestellten Bildern jedenfalls durch Ersitzung erlangt habe. Auf die Begründung des Urteils wird Bezug genommen (Bl. 93-99 d.A.).

[15] Gegen dieses, ihm am 16.9.2015 zugestellte Urteil richtet sich die am 9.10.2015 beim OLG eingegangene und mit am 26.10.2015 beim OLG eingegangenen Schriftsatz begründete Berufung des Klägers, die dessen erstinstanzliches Klagebegehren wie auch sein Abweisungsbegehren hinsichtlich der Widerklage vollumfänglich weiterverfolgt.

[16] In der Berufungsinstanz haben die Parteien ihr erstinstanzliches Vorbringen wiederholt und vertieft.

[17] Der Kläger, Widerbeklagte und Berufungskläger beantragt, das Urteil des LG Ansbach 20 891/14 aufzuheben und den Beklagten zu verurteilen, die Freigabe der beim AG Ansbach Hinterlegungsstelle - unter dem Aktenzeichen HL 11/2010 hinterlegten Gemälde von H. P. "X“ an den Kläger und Berufungskläger zu bewilligen, hilfsweise, den Rechtsstreit zur weiteren Behandlung und Entscheidung - auch über die Kosten des Berufungsverfahrens - an das LG Ansbach zurückzuverweisen.

[18] Der Beklagte, Widerkläger und Berufungsbeklagte beantragt, die Berufung zurückzuweisen.

[19] Der Senat hat in der mündlichen Verhandlung vom 26.7.2017 darauf hingewiesen, dass das Vorbringen des Klägers zu einer Schenkung der Bilder durch den Maler an dessen Tochter C. S., geb. P., zum Diebstahl dieser Gemälde sowie zu deren Echtheit jeweils bestritten ist und dass insoweit seitens des Klägers kein Beweis angetreten wurde. Innerhalb hierzu eingeräumter Schriftsatzfrist erfolgte eine Stellungnahme des Klägers (Schriftsätze des Klägervertreters vom 22.8.2017, BI. 168181 d.A., und vom 23.8.2017, Bl. 182-197 d.A.)

[20] Im Übrigen wird hinsichtlich des beiderseitigen Parteivortrags auf die gewechselten Schriftsätze verwiesen.

[21] B. Die zulässige Berufung des Klägers bleibt in der Sache ohne Erfolg. Das LG hat im Ergebnis zutreffend die Klage abgewiesen sowie der Widerklage stattgegeben.

[22] Allerdings können die klage- und widerklagegegenständlichen Freigabeansprüche nicht auf § 985 BGB oder auf $\S 1007$ BGB gestützt werden. Richtige Anspruchsgrundlage ist vielmehr $\S 812$ Abs. 1 S. 1 Alt. 2 BGB (siehe unten I). Hierbei kann offen bleiben, ob - im Hinblick auf die vom Kläger behauptete Mitberechtigung seiner Schwester C. B., geb. S., als Miterbin nur eine zwischen diesen bestehende Erbengemeinschaft ak- 
tivlegitimiert wäre bzw. ob dem Widerkläger die von diesem allein erstrebte Freigabeerklärung des Widerbeklagten nutzt (siehe unten II).

[23] Die Klage bleibt bereits deshalb ohne Erfolg, weil der Kläger hinsichtlich einzelner Umstände, aus denen er seine Aktivlegitimation herleitet, beweisfällig geblieben ist (siehe unten III).

[24] Selbst wenn es sich bei den sichergestellten Gemälden um die von H. P. gefertigten Originale handeln würde, hätte der Beklagte und Widerkläger hieran jedenfalls Eigentum infolge Ersitzung gem. § 937 BGB erlangt. Das LG hat rechtfehlerfrei einen zehnjährigen Eigenbesitz des Beklagten für nachgewiesen erachtet; die gegen diese Beweiswürdigung gerichteten Angriffe der Berufung bleiben ohne Erfolg (siehe unten IV). Das LG hat weiter hinsichtlich der für eine Ersitzung relevanten Gut- bzw. Bösgläubigkeit des Beklagten ( $\$ 937$ Abs. 2 BGB) die Beweislast nicht verkannt (siehe unten V). Das LG hat schließlich rechtfehlerfrei den Nachweis einer Bösgläubigkeit des Beklagten nicht für geführt erachtet; auch die hiergegen gerichteten Angriffe der Berufung bleiben ohne Erfolg (siehe unten VI).

[25] Danach ist die Klage abzuweisen und der Widerklage stattzugeben. Die Vorschriften des Kulturgutschutzgesetzes gebieten insoweit keine andere Beurteilung (siehe unten VII).

[26] Die nachgelassenen Schriftsätze der Klagepartei führen nicht zur Wiedereröffnung der mündlichen Verhandlung (siehe unten VIII).

I.

[27] Die klage- und widerklagegegenständlichen Freigabeansprüche können entgegen der Ansicht der Parteien nicht auf $\S 985$ BGB oder auf § 1007 BGB gestützt werden. Die genannten Anspruchsgrundlagen richten sich jeweils gegen den Besitzer der herauszugebenden Sache; die Parteien haben indes keinen Besitz an den Gemälden.

[28] Richtige Anspruchsgrundlage für die beiderseitigen Begehren ist vielmehr $\S 812$ Abs. 1 S. 1 Alt. 2 BGB (,in sonstiger Weise auf Kosten eines anderen etwas ohne rechtlichen Grund erlangt"). Die Parteien haben aufgrund der Hinterlegung jeweils die Rechtsposition eines „Beteiligten“ im Hinterlegungsverfahren erlangt; ihr Streit geht darum, ob dies ohne rechtlichen Grund geschehen ist.

[29] 1. Die Hinterlegung der Gemälde durch die Staatsanwaltschaft am 18.2.2010/ 9.3.2010 (Anlage K16) erfolgte gem. $\S 372$ S. 2 BGB (Hinterlegung von Kostbarkeiten, wenn der Schuldner - hier: die Staatsanwaltschaft - infolge Ungewissheit über die Person des Gläubigers seine Herausgabepflicht diesem gegenüber nicht mit Sicherheit erfüllen kann). Die Staatsanwaltschaft hat dabei auf ihr Recht zur Rücknahme der hinterlegten Bilder ( 3376 Abs. 1 BGB) verzichtet und dies der
Hinterlegungsstelle erklärt ( $\$ 376$ Abs. 2 Nr. 1 BGB) sowie beide Parteien und die Schwester des Klägers Frau C. B., geb. S., als mögliche Empfangsberechtigte benannt (Anlage K16). Damit wurde die Staatsanwaltschaft von ihrer Rückgabeverpflichtung befreit (§ 378 BGB). Zugleich ist sie keine Hinterlegungsbeteiligte mehr, so dass eine Freigabeerklärung der Staatsanwaltschaft nicht mehr erforderlich ist (vgl. Grüneberg in: Palandt, BGB, 76. Aufl., § 380 Rn. 2)

[30] 2. Das Hinterlegungsverfahren richtet sich nach der zum Zeitpunkt der Hinterlegung noch (als Landesrecht) fortgeltenden Hinterlegungsordnung (HinterlO) vom 10.3.1937 (RGBI. 1937 Teil I S. 285; BGBI. III/FNA 300-15), die mit Wirkung ab 1.12.2010 durch das - im Wesentlichen inhaltsgleiche - Bayerische Hinterlegungsgesetz (BayHintG) vom 23.11.2010 ersetzt wurde (vgl. Art. 31 BayHintG). Danach sind Gemälde als Kostbarkeiten hinterlegungsfähig, sog. Werthinterlegung ( $\$ 5$ HinterlO; Art. 9 Abs. 1 Nr. 2 BayHintG).

[31] Damit die Hinterlegungsstelle an einen der Hinterlegungsbeteiligten herausgeben darf, bedarf es der (auch als „Freigabe" bezeichneten) Bewilligung durch die übrigen Beteiligten (§ 12, § 13 Abs. 1, Abs. 2 S. 1 Nr. 1 HinterlO; Art. 18 Abs. 1 Abs. 2 Nr. 1; Art. 19 Abs. 2 Nrn. 1 und 3; Art. 20 Abs. 1 Nr. 2 BayHintG) oder alternativ einer rechtskräftigen gerichtlichen Entscheidung, die die Empfangsberechtigung eines Beteiligten mit Wirkung gegen die übrigen Beteiligten feststellt ( $§ 13$ Abs. 2 S. 1 Nr. 2 HinterlO; Art. 20 Abs. 1 Nr. 3 BayHintG).

[32] Beide Parteien wie auch die Schwester des Klägers Frau C. B., geb. S., sind jeweils Beteiligte des Hinterlegungsverfahrens im Sinne von § 13 HinterlO / Art. 18-20 BayHintG, nachdem die Staatsanwaltschaft sie als solche benannt hat (vgl. BGH, Urt. v. 30.1.2015 - V ZR 63/13, NJW 2015, 1678, Tz. 9 bei juris).

[33] Zwar entfällt die Beteiligtenstellung eines von dem Hinterlegenden benannten Empfängers dann, wenn unzweifelhaft feststeht, dass er materiell nicht berechtigt ist; infolgedessen ist seine Bewilligung entbehrlich (BGH aaO mwN). Davon kann hier jedoch nicht ausgegangen werden.

[34] 3. Der (wahre) Berechtigte kann die Abgabe einer entsprechenden Bewilligung der Herausgabe („Freigabeerklärung") gem. § 812 Abs. 1 S. 1 Alt. 2 BGB von den übrigen Prätendenten verlangen, die ihre Rechtsposition auf seine Kosten erlangt haben. Insoweit ist es ohne Bedeutung, ob die Voraussetzungen für eine Hinterlegung vorlagen. Ob ein diesbezüglicher Anspruch besteht, richtet sich dabei nicht nach dem Innenverhältnis zwischen den Prätendenten, sondern ausschließlich nach dem materiellen Rechtsverhältnis zwischen dem hinterlegenden Schuldner - hier der Staatsanwaltschaft - und dem Kläger (BGH, Urt. v. 30.1.2015 - V ZR 63/13, NJW 2015, 1678, Tz. 8 bei juris; Urt. v. 16.11.2012 - V ZR 179/11, ZIP 2013, 384, Tz. 10 bei juris; Urt. v. 7.12.2006 - IX ZR 161/04, NJW-RR 2007, 845, 846; Urt. v. 15.10.1999 - V ZR 141/98, NJW 2000, 291, 294; Urt. v. 13.11.1996 - VIII ZR 210/95, NJW-RR 1997, 495, Tz. 10 bei juris; 
Urt. v. 29.11.1989 - VIII ZR 228/88, BGHZ 109, 240, Tz. 10 bei juris; Sprau in: Palandt, BGB, 76. Aufl. § 812 Rn. 93; Grüneberg in: Palandt, aaO Einf $v \S 372$ Rn. 8).

\section{II.}

[35] Hierbei kann offen bleiben, ob - im Hinblick auf die vom Kläger behauptete Mitberechtigung seiner Schwester C. B., geb. S., als Miterbin - nur eine zwischen diesen bestehende Erbengemeinschaft zur Geltendmachung von Herausgabeansprüchen gegen die Hinterlegungsstelle aktivlegitimiert wäre bzw. ob dem Widerkläger die von diesem allein erstrebte Freigabeerklärung des Widerbeklagten nutzt oder ob dieser zur Empfangnahme der Bilder auch einer weiteren Freigabeerklärung der Schwester des Klägers bedarf. Diese Fragen sind anlässlich der Geltendmachung eines Herausgabeanspruchs gegen die Hinterlegungsstelle von dieser zu entscheiden.

[36] Eine Entscheidung des Senats zu diesen Fragen ist auch nicht möglich, nachdem nicht vorgetragen ist, ob die Erbengemeinschaft des Klägers mit seiner Schwester in Bezug auf die klagegegenständlichen Bilder bereits auseinandergesetzt ist oder noch besteht (vgl. § 2033 Abs. 2 BGB).

\section{III.}

[37] Die Klage bleibt bereits deshalb ohne Erfolg, weil der Kläger hinsichtlich einzelner Umstände, aus denen er seine Aktivlegitimation herleitet, beweisfällig geblieben ist.

[38] 1. Dies betrifft zunächst die Frage der Echtheit der hinterlegten Gemälde, also deren Identität mit den unstreitig vom Maler H. P. gefertigten Originalen.

[39] a) Der Beklagte hatte die Echtheit der Gemälde mit Nichtwissen bestritten; es sei nicht geklärt, ob es sich bei den bei ihm aufgefundenen Bildern tatsächlich um Originale oder um Kopien oder Fälschungen handele. Dieses Bestreiten ist gem. § 138 Abs. 4 ZPO zulässig.

[40] Der Kläger hatte vorgetragen, bei den sichergestellten Bildern handele es sich um die von H. P. stammenden Originale, deren Provenienz - entsprechend der Aussage des Zeugen Dr. F. B., des derzeitigen Leiters des H. P. Archivs, bei der Polizei zweifelsfrei feststehe; andernfalls würde der Rechtsstreit nicht geführt. Diesbezügliche Zweifel des Beklagten an der Echtheit würden nicht geteilt.

[41] Der im staatsanwaltlichen Ermittlungsverfahren von der Polizei vernommene Zeuge Dr. F. B. hatte dort ausgeführt, es handele sich mit Sicherheit um Originale (vgl. BI. $54 \mathrm{ff} ., 56$ der beigezogenen Ermittlungsakten). Im gerichtlichen Verfahren wurde dieser Zeuge weder benannt noch vernommen.

[42] Das LG hat die Frage der „Echtheit" der Gemälde offen gelassen (vgl. S. 7 der Urteilsgründe unter II).
[43] b) Diese Frage ist entscheidungserheblich. Der Klagevortrag würde den geltend gemachten Freigabeanspruch nur rechtfertigen können, wenn es sich bei den hinterlegten Bildern um Originalgemälde handelt. Lägen dagegen Kopien oder Fälschungen vor, wäre die Klage unschlüssig, da nicht dargelegt ist, aufgrund welcher Umstände der Kläger insoweit berechtigt sein könnte.

[44] c) Die Frage der Echtheit eines Gemäldes erfordert spezielle Fachkenntnisse, ist damit Sachverständigenfrage. Allein aus einem optischen Vergleich der sichergestellten Bilder mit den im Werkverzeichnis des Males H. P. enthaltenen Abbildungen der Originalgemälde vermag der Senat nicht zu beurteilen, ob es sich um Originale handelt. Soweit der Kläger mit nachgelassenen Schriftsätzen vom 22.8.2017 und 23.8.2017 Bezug nimmt auf ein behauptetes Original-Polaroid-Foto des Bildes "X" (bezeichnet als Anlage BK7), war ein solches diesen Schriftsätzen nicht beigefügt; stattdessen wurde mit Schriftsatz vom 31.8.2017, bei Gericht eingegangen am 4.9.2017, eine diesbezügliche Abbildung vorgelegt. Im Übrigen würde auch ein optischer Vergleich der sichergestellten Bilder mit einem solchen Polaroid-Foto bzw. mit der vorgelegten Abbildung nicht zum Nachweis der Echtheit taugen.

[45] Auch bloßer Zeugenbeweis wird zum Nachweis der Originalität regelmäßig nicht ausreichen, da ein - auch sachverständiger - Zeuge nur über eigene Wahrnehmung von Tatsachen und tatsächlichen Vorgängen berichten kann. Soweit der von der Polizei als Zeuge vernommene Leiter des H. P. Archivs Dr. F. B. im staatsanwaltlichen Ermittlungsverfahren Ausführungen zur Echtheit der Gemälde getätigt hat, ist zudem nicht dargelegt, dass und warum Dr. B. über entsprechende (welche?) Spezialkenntnisse und hinreichend sicheres Fachwissen verfügt und welche eigenen Wahrnehmungen er hinsichtlich der sichergestellten und hinterlegten Gemälde gemacht haben soll.

[46] Auch soweit der Kläger mit nachgelassenen Schriftsätzen vom 22.8.2017 und vom 23.8.2017 vorgetragen hat, "das P.-Archiv bzw. das Werkverzeichnis ist heute die allgemein anerkannte Institution zu Fragen der Echtheit der Bilder..." und zum Nachweis dieser Behauptung Vernehmung des Zeugen Dr. F. B., des Leiters des H. P. Archivs, angeboten hat, ist eine Beweisaufnahme nicht veranlasst. Weiterhin liegt kein Sachvortrag dazu vor, dass und warum der benannte Zeuge über für die Echtheitsbeurteilung erforderliche Spezialkenntnisse und hinreichend sicheres Fachwissen verfügt und welche eigenen Wahrnehmungen er hinsichtlich der Echtheit der sichergestellten und hinterlegten Gemälde gemacht haben soll. Vorgenanntes Beweisangebot wäre - jedenfalls auf die Echtheit der Bilder bezogen - vielmehr ein unzulässiger Ausforschungsbeweisantrag.

[47] Nachdem seitens des Klägers für die Frage der Echtheit kein Beweis angetreten ist, ist der Nachweis der Echtheit der klagegegenständlichen Gemälde nicht geführt. 
[48] 2. Der Kläger blieb weiter beweisfällig hinsichtlich seiner Behauptung, der Maler H. P. habe die beiden Bilder zu Lebzeiten an seine Tochter C. S., geb. P., geschenkt.

[49] a) Der Beklagte hatte „die behauptete lückenlose Provenienz" der Bilder und "die hieraus abgeleitete Aktivlegitimation" bestritten und u.a. das Fehlen „entsprechender Erbschaftsnachweise u.a. Übertragungsnachweise" gerügt. Damit ist auch die vorgetragene Schenkung der Bilder bestritten. Dieses Bestreiten mit Nichtwissen ist gem. § 138 Abs. 4 ZPO zulässig.

[50] Das LG hat zum Vorliegen einer Schenkung keine Feststellungen getroffen.

[51] b) Diese Frage ist entscheidungserheblich. Der Klagevortrag würde den geltend gemachten Freigabeanspruch nur rechtfertigen können, wenn das Eigentum an den hinterlegten Bildern vom Maler H. P. (etwa infolge einer Schenkung) an dessen Tochter C. S., geb. P. - aus deren Rechtsnachfolge als (Mit-) Erbe der Kläger seine Rechtsposition herleitet - übergegangen wäre. Wäre eine Schenkung dagegen nicht erfolgt, wäre nicht ersichtlich, aufgrund welcher Umstände der Kläger (und dessen Schwester C. B., geb. S.) das von ihm behauptete Eigentum erlangt hätten. Dies gilt insbesondere hinsichtlich einer Erlangung im Wege der Erbfolge nach H. P., zu der nichts vorgetragen ist (und die im Hinblick auf das unstreitige Vorhandensein mehrerer Geschwister der C. S., geb. P., unklar ist).

[52] c) Seitens des Klägers ist für die behauptete Schenkung erstinstanzlich nicht explizit Beweis angeboten worden.

[53] Die im staatsanwaltlichen Ermittlungsverfahren von der Polizei vernommene Zeugin H. (eine Nichte der C. S., geb. P.) hatte dort ausgeführt, die Bilder gehörten nicht der Erbengemeinschaft H. P., sondern seien im Privatbesitz von C. S. gewesen (vgl. Bl. 57 f. der beigezogenen Ermittlungsakten). Im gerichtlichen Verfahren wurde diese Zeugin indes weder benannt noch vernommen. Ihre Aussage bei den Ermittlungsbehörden lässt auch nicht erkennen, was die Zeugin unter "Privatbesitz" versteht und woraus sie ihre entsprechenden Erkenntnisse herleitet.

[54] Die vom Kläger vorgelegten Kopien aus dem Werkverzeichnis des Malers H. P. (Anlagen K17, K18, K18a, BK1) weisen hinsichtlich der Gemälde "X" und "Y" jeweils den Textvermerk „Provenienz: C. S.-P., Stuttgart" auf.

[55] Der Senat hält auch in Anbetracht vorgenannter Umstände den Nachweis der behaupteten Schenkung für nicht geführt. Dabei wird nicht verkannt, dass den Werkkatalogen von Künstlern in der Regel eine hohe Bedeutung zukommt, weil sie auf umfangreichen, jahrelangen Recherchen und oft schwer zugänglichen Quellen und auf in jahrelanger Detailarbeit erworbenen Spezialkenntnissen - im Streitfall wohl insbesondere auch des Dr. R. P., Bruder der C. S., geb. P. und Onkel des Klägers, vormaliger Leiter des H. P. Archivs in München - beru- hen, wobei neben der künstlerischen Beurteilung in der Regel auch eine eingehende Überprüfung der Provenienz erfolgt (vgl. LG Köln, Urt. v. 15.06.2011 - 91 O 87/07, juris, Tz. 24). Andererseits lassen die Provenienzvermerke nicht erkennen, aus welchen Umständen der/die Verfasser des Werkverzeichnisses seine/ihre entsprechenden Erkenntnisse herleitet/herleiten; die behauptete Schenkung wird insbesondere weder nach Zeitpunkt noch nach Anlass oder sonstigen Umständen näher konkretisiert. Die Angaben im Werkverzeichnis erscheinen auch deshalb nicht bedenkenlos glaubhaft, weil hinsichtlich der beiden Gemälde dort jeweils weiter vermerkt ist: „Standort unbekannt (nach RP 1986 gestohlen)", wohingegen der Kläger selbst behauptet, dass diese Gemälde 2009 sichergestellt wurden, ihr Standort mithin seit diesem Datum bekannt ist; insoweit wird indes nicht verkannt, dass mit nachgelassenen Schriftsätzen des Klägers vom 22.8.2017 und vom 23.8.2017 nunmehr vorgetragen wird, das Werkverzeichnis sei im Jahre 2004 - und damit bereits vor dem Wiederauffinden der beiden Bilder - herausgegeben worden.

[56] Soweit der Kläger mit nachgelassenen Schriftsätzen vom 22.8.2017 und vom 23.8.2017 auf ein behauptetes, vor 1986 aufgenommenes Original-Polaroid-Foto des Bildes "X“ (bezeichnet als Anlage BK7) - das nicht vorgelegt wurde - sowie auf eine zugehörige handschriftliche Notiz seiner Mutter „Besitz C. S." - die ebenfalls nicht vorgelegt wurde - bzw. mit (nicht nachgelassenem) weiteren Schriftsatz vom 31.8.2017 vorgelegte diesbezügliche Abbildungen Bezug genommen hat und auf die Bestimmbarkeit des Alters des Fotos wie der Authentizität der Beschriftung verweist, ergäbe sich hieraus allenfalls Besitz der C. S., geb. P., an dem genannten Bild, nicht indes, aufgrund welcher Umstände sie den Besitz erlangt hat, ob ihr dieses Bild mithin vom Maler H. P., ihrem Vater, geschenkt worden war.

[57] Soweit der Kläger mit den nachgelassenen Schriftsätzen weiter vorgetragen hat, "das P.-Archiv bzw. das Werkverzeichnis ist heute die allgemein anerkannte Institution zu Fragen ... der Eigentumsverhältnisse" an den Bildern und zum Nachweis dieser Behauptung Vernehmung des Zeugen Dr. F. B., des Leiters des H. P. Archivs, angeboten hat, ist eine Beweisaufnahme nicht veranlasst. Es ist nicht vorgetragen und auch nicht ersichtlich, welche konkreten Wahrnehmungen der Zeuge hinsichtlich der behaupteten Schenkung bekunden soll. Vorgenanntes Beweisangebot wäre - jedenfalls auf die Schenkung der Bilder bezogen - vielmehr ein unzulässiger Ausforschungsbeweisantrag.

[58] Auch bei Zusammenschau aller erörterten Gesichtspunkte ist der Senat nicht mit der erforderlichen Gewissheit davon überzeugt, dass der Maler H. P. die beiden Bilder zu Lebzeiten an seine Tochter C. S., geb. P., geschenkt hat. Diese Wertung scheint zwar möglich, indes nicht zwingend. Insbesondere könnte selbst aus einem zeitweisen Besitz von C. S. an den Gemälden nicht mit hinreichender Sicherheit auf deren Übereignung (im Wege einer Schenkung) geschlossen werden. 
[59] 3. Hinsichtlich der vom Beklagten zulässig mit Nichtwissen bestrittenen Erbfolge nach C. S., geb. P., sieht der Senat dagegen den Nachweis einer diesbezüglichen (Mit-)Berechtigung des Klägers geführt.

[60] Der Kläger hatte behauptet, nach dem Tod seiner Mutter C. S., geb. P., am 12.9.1993 seien er, seine Schwester C. B., geb. S., sowie sein Vater Prof. Dr. jur. F. S. deren Miterben zu je 1/3 geworden. Nach dem Tod seines Vaters seien er sowie seine Schwester Caroline B., geb. S., dessen Miterben zu je $1 / 2$ geworden. Diese Erbfolge wird durch das hierzu vorgelegte Anlagenkonvolut K15 nachgewiesen; hieraus ergibt sich die behauptete Erbfolge (Erbschein hinsichtlich C. S., geb. P., sowie Nachlassakte hinsichtlich Prof. Dr. F. S.). Auch die mit nachgelassenen Schriftsätzen des Klägers vom 22.8.2013 und vom 23.8.2013 vorgelegten diesbezüglichen Urkunden (Anlage BK8, BK9) belegen die genannte Erbfolge.

[61] Wäre C. S., geb. P., mithin Eigentümerin der beiden Gemälde gewesen, so wären diese im Wege der (mehrfachen) Universalsukzession auf den Kläger und dessen Schwester C. B., geb. S., in Erbengemeinschaft übergegangen.

[62] Daran hätte der vom Kläger behauptete Diebstahl der beiden Bilder im Jahr 1986 nichts geändert. Im Falle des Diebstahls erlangt der Dieb nur den Besitz an den gestohlenen Sachen und erwirbt nicht auch deren Eigentum. Als Nichtberechtigter kann er bei Weiterveräußerung, Schenkung etc. auch nicht das Eigentum übertragen (da insoweit eine Einigung mit dem wirklichen Eigentümer der Sache erforderlich wäre, § 929 BGB). Ein gutgläubiger Erwerb ( $\$ 932$ BGB) ist bei gestohlenen Sachen nicht möglich, § 935 BGB, scheidet somit (im Falle des Diebstahls) auch für den Beklagten bzw. dessen Stiefvater J. S. aus.

[63] 4. Da aufgrund der vorgenannten Umstände hinsichtlich der Echtheit der Gemälde (siehe oben B III 1) sowie hinsichtlich deren Schenkung an C. S., geb. P. (siehe oben B III 2) die Voraussetzungen einer Rechtsinhaberschaft und damit Aktivlegitimation des Klägers nicht nachgewiesen sind, bleibt das Klagebegehren bereits aus diesem Grund ohne Erfolg.

[64] 5. Der Hinweis des Klägers in den nachgelassenen Schriftsätzen vom 22.8.2017 und vom 23.8.2017 darauf, dass das LG „offenkundig keine Zweifel an der Aktivlegitimation des Klägers gehabt" habe und auch keinen diesbezüglichen Hinweis nach § 139 ZPO erteilt habe, liegt neben der Sache.

[65] Zum einen hat das LG hinsichtlich der insoweit für die Aktivlegitimation maßgeblichen Umstände der Echtheit der Gemälde (oben B III 1) und deren Schenkung durch H. P. an dessen Tochter C. S., geb. P. (oben B III 2) keine Feststellungen getroffen, an die der Senat gem. §529 Abs. 1 Nr. 1 ZPO gebunden sein könnte. Nachdem das LG sein Urteil darauf gestützt hat, dass der Beklagte jedenfalls im Wege der Ersitzung Eigentum an den Bildern erlangt habe, kam es für dessen Entscheidung auf Fragen der Aktivlegitimation auch nicht an.

[66] Zum anderen war die Erteilung eines Hinweises gem. § 139 ZPO nicht geboten. Bei dem Umstand, dass bestrittene entscheidungserhebliche Tatsachen des Beweises seitens der insoweit beweisbelasteten Partei bedürfen, handelt es sich um eine Selbstverständlichkeit, auf die grundsätzlich nicht hingewiesen zu werden braucht. In Anbetracht des expliziten Bestreitens sowohl der Echtheit der Gemälde als auch deren Schenkung durch H. P. an dessen Tochter C. S., geb. P., seitens des Beklagten musste für den Kläger die Erforderlichkeit einer diesbezüglichen Beweisführung offensichtlich sein. Demgemäß ist eine Partei auf die Notwendigkeit der Benennung von Beweismitteln nur dann hinzuweisen, wenn sich aus dem übrigen Vorbringen dieser Partei ergibt, dass das Unterbleiben des Beweisantritts auf einem Versehen oder auf einer erkennbar falschen Beurteilung der Rechtslage - z.B. der Beweislast - beruht (vgl. Zöller/Greger ZPO, 31. Aufl., § 139 Rn. 16 mwN). Dass derartige Umstände vorgelegen hätten, wird seitens des Klägers weder vorgetragen noch ist dies ersichtlich.

[67] Unabhängig hiervon hat der Senat überobligationsmäßig in der mündlichen Verhandlung vom 26.7.2017 einen rechtlichen Hinweis gem. § 139 ZPO dahingehend erteilt, dass die genannten, für die Aktivlegitimation des Klägers maßgeblichen Umstände wie auch der weiter vorgetragene behauptete Diebstahl der Gemälde jeweils seitens des Beklagten bestritten sind und insoweit keine Beweisangebote des Klägers erfolgt sind. Die in den nachgelassenen Schriftsätzen der Klagepartei erfolgten diesbezüglichen Ausführungen rechtfertigen indes, wie oben ausgeführt, keine andere Beurteilung der nicht nachgewiesenen Echtheit der beiden Bilder wie auch deren nicht nachgewiesener Schenkung durch den Maler H. P. an dessen Tochter C. S., geb. P..

IV.

[68] Unabhängig davon hat der Beklagte - selbst wenn es sich bei den sichergestellten Gemälden um die von H. P. gefertigten Originale handeln würde - hieran jedenfalls Eigentum infolge Ersitzung gem. § 937 BGB erlangt.

[69] Wer eine bewegliche Sache zehn Jahre in Eigenbesitz hat, erwirbt das Eigentum (Ersitzung), § 937 Abs. 1 BGB. Eigenbesitzer ist, wer eine Sache als inm gehörend besitzt, § 872 BGB. Die Ersitzungsfrist beginnt mit Erwerb des Eigenbesitzes; dieser muss in der Folge ununterbrochen (Ausnahme: § 940 Abs. 2 BGB) zehn Jahre lang bestehen.

[70] Die Ersitzung ist ausgeschlossen, wenn der Erwerber bei dem Erwerb des Eigenbesitzes nicht in gutem Glauben ist oder wenn er später erfährt, dass ihm das Eigentum nicht zusteht, § 937 Abs. 2 BGB. 
[71] Bei der Ersitzung erwirbt der Ersitzende kraft Gesetzes originäres Eigentum; der bisherige Eigentümer verliert es. Ersitzung ist insbesondere auch an gestohlenen Sachen möglich (Herrler in: Palandt, BGB, 76. Aufl. Vorb v § 937 Rn. 1).

[72] Das LG hat rechtfehlerfrei einen zehnjährigen Eigenbesitz des Beklagten als Voraussetzung einer Ersitzung für nachgewiesen erachtet. Die gegen diese Beweiswürdigung gerichteten Angriffe der Berufung bleiben ohne Erfolg.

[73] 1. Der Ersitzende hat die Darlegungs- und Beweislast für seinen zehnjährigen ununterbrochenen Eigenbesitz. Der Beklagte hat mithin seinen Vortrag zu beweisen, er habe die beiden Gemälde länger als zehn Jahre in Eigenbesitz gehabt.

[74] 2. Der Eigenbesitz des Beklagten hat am 1.10.2009 geendet. Durch die Sicherstellung und Beschlagnahme der Bilder zu diesem Datum hat der Beklagte seinen Eigenbesitz hieran verloren; in der Folge befanden sich die Bilder in Gewahrsam der Polizei, so dass der Beklagte keine tatsächliche Sachherrschaft mehr besaß (§§ 854 Abs. 1, 856 Abs. 1 BGB). Damit wurde die Ersitzung unterbrochen ( $\S 940$ Abs. 1 BGB). Ein Fall des $\S 940$ Abs. 2 BGB liegt nicht vor, da der Beklagte Eigenbesitz nicht binnen Jahresfrist wiedererlangt hat.

[75] Zwar wäre auch mittelbarer Besitz ( $\$ 868$ BGB) ausreichend für Eigenbesitz (Wiegand in: Staudinger, BGB, Neubearbeitung 2017, § 937 Rn. 3; Lenders in: Herberger/Martinek/Rüßmann/Weth/ Würdinger, jurisPK-BGB, 8. Aufl. 2017, § 937 BGB Rn. 6). Dieser setzt ein sog. Besitzmittlungsverhältnis (constitutum possessorium) zwischen unmittelbarem und mittelbarem Besitzer voraus, das privat- oder öffentlich-rechtlicher Natur sein kann und durch Vertrag, Gesetz oder Hoheitsakt begründet werden kann (Herrler in: Palandt, BGB, 76. Aufl. §868 Rn. $6 \mathrm{mwN}$ ). Die Beschlagnahme eines Gegenstandes kann (kraft Hoheitsakt) grundsätzlich auch ein derartiges Besitzmittlungsverhältnis zwischen Beschlagnahmebehörde und Vorbesitzer begründen; so kann etwa bei Pfändung eines angeblichen Herausgabeanspruchs aus einem Besitzmittlungsverhältnis mehrstufiger mittelbarer Besitz ( $\$ 871 \mathrm{BGB}$ ) begründet werden (vgl. BGH, Urt. v. 14.1.1993 - IX ZR 238/91, NJW 1993, 935, Tz. 10 bei juris; Herrler in: Palandt, BGB, 76. Aufl. § 868 Rn. 9). Indes wird durch eine polizeiliche oder staatsanwaltliche Beschlagnahme ein Besitzmittlungsverhältnis nicht begründet (VG Köln, Urt. v. 29.3.2012 - 20 K 2270/11, juris Tz. 25f.; OLG Hamm, Beschluss vom 12.7.1988 - 7 W 28/88, VRS 75, 419, juris; OLG München, NJW 1982, 2330).

[76] Der Eigenbesitz des Beklagten hat somit mit Beschlagnahme der Bilder am 1.10.2009 geendet.

[77] 3. Die Wahrung des Ersitzungszeitraums würde damit voraussetzen, dass der Beklagte den Nachweis führt, spätestens seit 1.10.1999 ununterbrochenen Eigenbesitz an den beiden Gemälden innegehabt zu haben.
[78] Das LG hat ausgeführt, nach dem Ergebnis der Beweisaufnahme sei es davon überzeugt, dass die Bilder jedenfalls seit mindestens 1998 in Besitz des Beklagten gewesen seien (S. 5 der Urteilsgründe unter I 1).

[79] Die Berufung rügt die entsprechende Beweiswürdigung als fehlerhaft. Das LG habe diesbezügliche Widersprüche in den Zeugenaussagen nicht beachtet, insbesondere da nach den Angaben der Zeugen ein Besitz erst ab "ca. ... 2000" nachgewiesen sei (so dass ein 10jähriger Eigenbesitz nicht nachgewiesen sei).

[80] Die diesbezüglichen Angriffe der Berufung gehen fehl.

[81] a) Da die Berufung - abweichend von ihrer früheren Funktion als vollwertige zweite Tatsacheninstanz - nunmehr in erster Linie der Fehlerkontrolle und Fehlerbeseitigung dient, ist das Berufungsgericht an die vom Gericht des ersten Rechtszugs festgestellten Tatsachen grundsätzlich gebunden; eine erneute Tatsachenfeststellung ist nur als Ausnahme vorgesehen, soweit die erste Instanz die Feststellungen nicht vollständig und überzeugend getroffen hat (§529 Abs. 1 Nr. 1 ZPO). Die Beweiswürdigung ist grundsätzlich Sache des Tatrichters. Zwar können sich Zweifel an der Richtigkeit und Vollständigkeit entscheidungserheblicher Tatsachen auch aus der Möglichkeit unterschiedlicher Wertungen ergeben. Hat sich aber das Erstgericht mit den Beweisergebnissen umfassend und widerspruchsfrei auseinandergesetzt, ist die Würdigung also vollständig und rechtlich möglich und verstößt sie nicht gegen Denkgesetze oder Erfahrungssätze und ist auch das Berufungsgericht von der Richtigkeit der erstinstanzlichen Beweiswürdigung überzeugt, so sind die Feststellungen bindend. Eine Partei kann dann nicht in zulässiger Weise ihre eigene Würdigung an die Stelle derjenigen des Erstgerichts setzen (vgl. BGH, Urt. v. 9.3.2005 - VIII ZR 266/03, BGHZ 162, 313).

[82] b) Im Rahmen dieser beschränkten Überprüfbarkeit ist die Wertung des LG, nach dem Ergebnis der Beweisaufnahme sei Eigenbesitz des Beklagten jedenfalls seit 1998 nachgewiesen, nicht zu beanstanden. Das LG hat sich mit den erhobenen Beweisen umfassend und vollständig auseinandergesetzt und insbesondere die Aussagen der Zeugen ausführlich gewürdigt. Die hiergegen von der Berufung erhobenen Rügen rechtfertigen keine abweichende Beurteilung. Die nach § 286 ZPO erforderliche Überzeugung des Richters erfordert keine absolute oder unumstößliche Gewissheit und auch keine „an Sicherheit grenzende Wahrscheinlichkeit", sondern nur einen für das praktische Leben brauchbaren Grad von Gewissheit, der Zweifeln Schweigen gebietet, ohne sie völlig auszuschließen (vgl. BGH, Urt, v. 18.6.1998 - IX ZR 311/95, NJW 1998, 2969, 2971). Die Sichtweise dess ist vollständig und rechtlich möglich und verstößt nicht gegen Denkgesetze oder Erfahrungssätze, ist damit für den Senat bindend. Die Berufung setzt insoweit lediglich unzulässiger Weise ihre eigene Beweiswürdigung an die Stelle derjenigen des Gerichts: 
[83] aa) Soweit die Berufung behauptet, die Zeugen M. und M. H. hätten jeweils bestätigt, dass die Bilder "um 2000" in die Familie gekommen seien, trifft dies nicht zu. Die Zeugin M. H. hat vielmehr nicht nur ausgesagt, "dass die Bilder schon so ca. 15 Jahren in der Familie sind", sondern auch, dass ihre Tochter K. (geb. 6.10.1980) ein Bild "schon vor langer Zeit, also in ihrer Kindheit" abgemalt hat, dass die Bilder "bei der Kommunion von A." schon längere Zeit im Haus waren und "nicht erst kurz vor der polizeilichen Beschlagnahme erworben (wurden). Dies war so Mitte der 90`er Jahre“. Der (am 26.6.1983 geborene) Zeuge M. H. hat ausgesagt, dass die Bilder „eigentlich schon immer bei uns irgendwo hingen" und dass er "wohl mit 15 Jahren diese Bilder das erste Mal wirklich registriert habe".

[84] Aus den Aussagen der Zeugen kann auch nicht gefolgert werden, dass die Bilder erst 2000 in Besitz des Beklagten kamen. Ersichtlich haben die Zeugen jeweils nur Schätzwerte angegeben. Aus der Aussage der Zeugin M. H., "dass die Bilder schon so ca. 15 Jahren in der Familie sind", kann indes nicht geschlossen werden, dass sie erst 15 Jahre vor Vernehmung der Zeugin (am 28.7.2015), mithin erst im Jahr 2000 erworben wurden. Erst recht kann aus der Angabe des Zeugen M. H., er habe "wohl mit 15 Jahren diese Bilder das erste Mal wirklich registriert", kein Schluss auf das Erwerbsdatum derart gezogen werden, dass die Bilder erst zu diesem Zeitpunkt angeschafft wurden (abgesehen davon, dass der Zeuge bereits 1998 seinen 15. Geburtstag hatte).

[85] bb) Die Zeugin K. H. führte aus, „die Bilder hängen schon sehr lange bei uns herum", sie habe als achtjähriges Kind "das Bild mit den $Y$ auch schon mal abgemalt“. Die Berufung rügt, damit setze sich die Zeugin in Widerspruch mit den Angaben des Beklagten, er habe die Bilder erst 1993 erlangt. Auch diese Behauptung trifft nicht zu. Der Beklagte hat nie ausgeführt, er habe die Bilder erst 1993 geschenkt bekommen, vielmehr (vgl. S. 3 des Urteils), "er habe die Gemälde jedenfalls vor 1993 geschenkt bekommen".

[86] cc) Von der Berufung gesehene Widersprüche in den Aussagen der Zeugen und den Angaben des Beklagten bestehen nicht. Ersichtlich haben alle Zeugen hinsichtlich des Zeitpunktes, in dem das Bild in Besitz des Beklagten gelangt ist, Schätzwerte erklärt. Eine von der Berufung vermisste Auseinandersetzung des Urteils mit derartigen Widersprüchen war deshalb nicht veranlasst.

[87] Ferner kann auch nicht übersehen werden, dass - falls man von einer nicht widerlegten Schenkung der Gemälde durch den Stiefvater J. S. ausgeht (siehe hierzu unten VI) - dieser bereits im Jahr 1993 verstorben ist; die vorgetragene Schenkung hat indes noch zu dessen Lebzeiten stattgefunden.

[88] c) Hinsichtlich eines ununterbrochenen Eigenbesitzes des Beklagten während des gesamten Zeitraumes zwischen "mindestens 1998" und 1.10.2009 spricht für diesen die nicht widerlegte Vermutung des § 938 BGB.

\section{V.}

[89] Das LG hat weiter hinsichtlich der für eine Ersitzung relevanten Gut- bzw. Bösgläubigkeit des Beklagten (§ 937 Abs. 2 BGB) die Beweislast nicht verkannt.

[90] 1. Das LG hat ausgeführt, der Kläger trage die Beweislast für den mangelnden guten Glauben des Beklagten bei Besitzerwerb oder für dessen spätere Bösgläubigkeit (S. 6 der Urteilsgründe).

[91] Dies rügt die Berufung als rechtsfehlerhaft.

[92] 2. Wie sich aus der Formulierung des § 937 Abs. 2 BGB ergibt, wird der gute Glaube des Ersitzenden vermutet. Die Darlegungs- und Beweislast für fehlenden guten Glauben (die Bösgläubigkeit) des Ersitzenden bei Begründung des Eigenbesitzes oder für während der Dauer des zehnjährigen Eigenbesitzes erlangte positive Kenntnis der Nichtberechtigung hat deshalb grundsätzlich, wer die Ersitzung bestreitet und gegen den Ersitzenden einen Anspruch aus dem Eigentum an der Sache geltend machen will (OLG Celle, OLGR 2004, 70, Tz. 53 bei juris; LG Berlin Kunst und Recht 2009, 20, Tz. 40 bei juris; Herrler in: Palandt, BGB, 76. Aufl. § 937 Rn. 1; Kindl in: Bamberger/Roth, BeckOK-BGB, 41. Edition 2016, § 937 Rn. 10; Lenders in: Herberger/Martinek/Rüßmann/Weth/Würdinger, jurisPK-BGB, 8. Aufl. 2017, § 937 BGB Rn. 17; Baldus in: MünchKomm-BGB, 7. Aufl. 2017, § 937 Rn. 87; Wiegand in: Staudinger, BGB, Neubearbeitung 2017, § 937 Rn. 11), im Streitfall mithin der Kläger.

[93] Trotz dieser Beweislastverteilung trägt indes derjenige, der sich auf Ersitzung beruft, die (sekundäre) Darlegungslast hinsichtlich seiner Gutgläubigkeit für Erwerbsvorgänge in seiner Sphäre (LG Berlin Kunst und Recht 2009, 20, Tz. 41 bei juris). Den Beklagten trifft deshalb eine solche Darlegungslast hinsichtlich der von ihm vorgetragenen Schenkung seines Stiefvaters, nicht aber etwa hinsichtlich des behaupteten Diebstahls 1986 im Hause der Eltern des Klägers.

[94] Dieser sekundären Darlegungslast hat der Beklagte im Streitfall mit dem Vortrag genügt, er habe die beiden Gemälde mutmaßlich 1986/1987 von seinem - 1993 verstorbenen - Stiefvater J. S. geschenkt bekommen, Herr S. habe dabei geäußert, die Bilder von einem Antiquitätenhändler oder -sammler in Dinkelsbühl erworben zu haben. Eine weitergehende Konkretisierung, etwa nach Zeitpunkt, Anlass oder Belegen, kann in Anbetracht des Zeitablaufs und des Umstandes einer vorgetragenen Schenkung nicht verlangt werden.

[95] 3. Teile der Rechtsprechung schränken diese Beweislastverteilung neuerdings dahingehend ein, dass in dem Fall, in dem einem früheren Besitzer eine Sache gestohlen wurde oder sonst abhandengekommen ist, den Ersitzenden die volle Beweislast hinsichtlich sämtlicher Voraussetzungen des § 937 BGB treffen soll. Der Ersitzende habe demnach insbesondere auch seine Gutgläubigkeit darzulegen und zu beweisen. Dies 
folge aus dem in den $\S \S 932,935$ BGB zum Ausdruck kommenden gesetzgeberischen Willen, den Eigentümer einer gestohlenen Sache unter den besonderen Schutz des Gesetzes zu stellen (OLG Celle, GRUR-RR 2011, 24, Tz. 31 bei juris; zitiert bei Lenders in: Herberger/Martinek/Rüßmann/Weth/Würdinger, jurisPK-BGB, 8. Aufl. 2017, § 937 BGB Rn. 17, sowie bei Baldus in: MünchKomm-BGB, 7. Aufl. 2017, § 937 Rn. 89).

[96] Die Berufung stützt sich auf das zitierte Urteil des OLG Celle. Sie meint, es gebe zudem eine vergleichbare (aus $\$ 1006$ Abs. 1 S. 2 BGB hergeleitete) Rechtsprechung, nach der, wenn ein früherer Besitzer, dem die Sache abhandengekommen ist, gegen einen späteren Besitzer auf Herausgabe der Sache klage, der Beklagte beweisen müsse, dass der Kläger sein Eigentum an der Sache trotz des dieser infolge des Abhandenkommens anhaftenden Makels verloren habe (vgl. BGH, Urt. v. 19.12.1994 - II ZR 4/94, NJW 1995, 1292, Tz. 16 bei juris; Urt. v. 4.2.2002 - II ZR 37/00, NJW 2002, 2101, Tz. 7 bei juris; Urt. v. 10.11.2004 - VIII ZR 186/03, BGHZ 161, 90). Auch im Streitfall lege die aus §§ 1006 Abs. 1 S. 2, 1007 Abs. 2 S. 1 BGB folgende Beweislastverteilung nahe, dass sich - einen Diebstahl der Gemälde unterstellt - der Beklagte zur Begründung seines Eigentums nicht auf die Besitzvermutung des § 1006 BGB berufen könne, vielmehr nachweisen müsse, dass der Kläger sein Eigentum verloren habe.

[97] Der Senat folgt der oben zitierten Entscheidung des OLG Celle nicht. Würde man bei abhanden gekommenen Sachen contra legem - eine volle Beweislast des Ersitzenden auch für dessen guten Glauben annehmen, würde die Beweislastregelung des $\S 937$ Abs. 2 BGB insoweit völlig gegenstandslos. Eine Vergleichbarkeit der Fallkonstellation zum Herausgabeanspruch eines früheren Besitzers gegen einen späteren Besitzer besteht zudem nicht, nachdem es im Streitfall nicht allein um die Eigentumsvermutung der $\S \S 1006,1007$ BGB geht, sondern um die Begründung originären Eigentums an (ggf.) gestohlenen Sachen.

[98] 4. Letztlich kommt es auf diese Rechtsfrage jedoch nicht an, da im Streitfall bereits das Abhandenkommen der beiden Gemälde nicht zur Überzeugung des Senats feststeht, mithin die vom OLG Celle geforderten Voraussetzungen einer vollen Beweislast des Ersitzenden nicht festgestellt werden können.

[99] a) Der Kläger hatte vorgetragen, bei einem Einbruch unbekannter Täter in das Anwesen seiner Eltern H.-K.-Str. xx in Stuttgart am 18.11.1986 seien neben weiteren Kunstgegenständen auch 4 Ölgemälde des Malers H. P., u.a. die Bilder "X“ und " $\mathrm{Y}$ ", entwendet worden. Der Beklagte hatte bestritten, dass die gegenständlichen Bilder tatsächlich gestohlen wurden; eine „behauptete Meldung des Diebstahls der Bilder im Einzelnen“ sei nicht belegt. Der Kläger hat das diesbezügliche Bestreiten des Beklagten „als unzutreffend und unpassend zurückgewiesen".

[100] Das LG hat zu dieser Frage keine Feststellungen getrof-
[101] b) Für den von inm behaupteten Diebstahl der beiden Bilder ist der Kläger, der sich hierauf beruft, darlegungs- und beweispflichtig. Dieser Beweis muss nicht nur den Umstand dass überhaupt ein Wohnungseinbruch bzw. Diebstahl stattgefunden hat, sondern weitergehend auch die Entwendung der streitgegenständlichen zwei Gemälde erfassen.

[102] Seitens des Klägers ist für den behaupteten Diebstah erstinstanzlich nicht explizit Beweis angeboten worden.

[103] Aus dem vorgelegten Schreiben der Kriminalpolizei Stuttgart vom 15.12.1986 (Anlage K4) ergibt sich, dass wegen eines am 18.11.1986 stattgefundenen Einbruchs im Anwesen der Eltern des Klägers polizeiliche Ermittlungen geführt wurden.

[104] Der Umstand, dass seinerzeit die Originalgemälde "X" und " ${ }^{\prime \prime}$ im Anwesen der Eltern waren und bei dem Einbruch entwendet wurden, wird auch in den polizeilichen Ermittlungsakten (insbesondere in Anlage K4) thematisiert. Dieser Umstand beruht indes wohl (nur) auf Angaben der Geschädigten gegenüber der Polizei. Diese werden erhärtet durch eine Auflistung „Antiquitäten, Bilder und Kunstgegenstände im Hause..." vom 7.3.1969 (BI. 119 ff. der beigezogenen Ermittlungsakten), die auf S. 2 unten auch die beiden Bilder aufweist, wie auch durch die Ausschreibung der zwei Gemälde unter Abbildung derselben im „BKA - Bundeskriminalblatt" in einer entsprechenden Kunstdatenbank (BI. 90, 91, 93, 96 der beigezogenen Ermittlungsakten).

[105] Die im Ermittlungsverfahren gegen den Beklagten von der Polizei vernommene Zeugin $\mathrm{H}$. (eine Nichte der C. S, geb. P.) hatte dort ausgeführt, ihrer Erinnerung nach seien im Jahr 1986 bei einem von zwei Einbrüchen im Anwesen ihrer Tante u.a. auch die Bilder "Stilleben $\mathrm{Y}^{\prime \prime}$ und "X" entwendet worden (vgl. Bl. 57f. der beigezogenen Ermittlungsakten). Im gerichtlichen Verfahren wurde diese Zeugin indes weder benannt noch vernommen. Ihre Aussage bei den Ermittlungsbehörden lässt auch nicht erkennen, woraus die Zeugin ihre entsprechenden Erkenntnisse herleitet.

[106] Auch der im Ermittlungsverfahren gegen den Beklagten von der Polizei vernommene Zeuge Dr. F. B. hatte dort ausgeführt, die beiden Bilder seien gemäß den Angaben im Werksverzeichnis gestohlen. Im gerichtlichen Verfahren wurde auch dieser Zeuge indes weder benannt noch vernommen. Seine Aussage bei den Ermittlungsbehörden lässt auch nicht erkennen, woraus der Zeuge seine entsprechenden Erkenntnisse herleitet.

[107] Die vom Kläger vorgelegten Kopien aus dem Werkverzeichnis des Malers H. P. (Anlagen K17, K18, K18a, BK1) weisen hinsichtlich der Gemälde "X" und "Y" jeweils den Textvermerk "Standort unbekannt (nach RP 1986 gestohlen)" auf, wobei hinsichtlich des Beweiswertes dieser Vermerke auf obige Ausführungen (siehe unter $\mathrm{B}$ III $2 \mathrm{c}$ ) verwiesen wird. fen. 
[108] Der Senat hält auch in Anbetracht vorgenannter Umstände den Nachweis eines Diebstahls gerade auch der beiden streitgegenständlichen Gemälde für nicht geführt. Die Ermittlung oder Verurteilung eines diesbezüglichen Straftäters wurde nicht bekannt und ist auch nicht ersichtlich. Auch hinsichtlich etwaiger, die beiden Bilder betreffender Schadensmeldungen an eine Versicherung ist nichts dargelegt.

[109] Auch die vom Kläger in den nachgelassenen Schriftsätzen vom 22.8.2017 und vom 23.8.2017 vorgetragenen weiteren Gesichtspunkte reichen zum Nachweis eines Diebstahls der beiden klagegegenständlichen Bilder nicht aus. Der Hinweis auf einen bereits am 20.12.1984 stattgefundenen anderen behaupteten Diebstahl und der diesbezüglich vorgelegte Schriftverkehr des Prof. Dr. F. S. (Anlage BK2) sind insoweit unbehelflich. Die nunmehr vorgelegten Inventarlisten vom 7.3.1969 (Anlage BK3) und vom 8.2.1985 (Anlage BK4) sowie der testamentarische Verweis der Mutter des Klägers C. S., geb. P., vom 10.10.1988 (Anlage BK5) und des Vaters des Klägers Prof. Dr. F. S. vom 11.11.1988 (Anlage BK6) auf - im Einzelnen nicht näher bezeichnete - zum Nachlass zugehörige Gemälde belegen einen Diebstahl der streitgegenständlichen Bilder nicht.

\section{VI.}

[110] Das LG hat schließlich rechtfehlerfrei den Nachweis einer Bösgläubigkeit des Beklagten nicht für geführt erachtet; auch die hiergegen gerichteten Angriffe der Berufung bleiben ohne Erfolg.

[111] 1. Das LG hat ausgeführt, der Kläger habe nicht zur Überzeugung des Gerichts nachgewiesen, dass der Beklagte zum Zeitpunkt des Erwerbs des Eigenbesitzes bösgläubig war oder dies später wurde (S. 6 der Urteilsgründe).

[112] Soweit im Urteil (auf S. 4 unter I vor 1) ausgeführt ist „Vielmehr ist das Gericht auf Grund der durchgeführten Beweisaufnahme davon überzeugt, dass der Beklagte zum Zeitpunkt des Erwerbs der Bilder ... hinsichtlich der Provenienz der Bilder gutgläubig war", folgt daraus nichts anderes. Zwar könnte diese Passage so verstanden werden, als sei - unabhängig von der Beweislast - der Nachweis der Gutgläubigkeit geführt. Dies widerspricht jedoch bereits dem unmittelbar davorstehenden Satz „Dem Kläger ist es nicht gelungen, den mangelnden guten Glauben des Beklagten ... nachzuweisen“. Auch lässt die Urteilsbegründung nicht erkennen, dass und warum das Gericht den Nachweis der Gutgläubigkeit als geführt angesehen hat; vielmehr geht die Begründung dahin, der Nachweis der Bösgläubigkeit sei nicht geführt.

[113] Die Berufung rügt insoweit eine unzureichende und rechtsfehlerhafte Beweiswürdigung.

[114] 2. Bösgläubigkeit bei Besitzerwerb bedeutet Kenntnis oder grob fahrlässige Unkenntnis von der fehlenden Berechtigung des Veräußerers (siehe oben B IV).
[115] Unter der gem. § 937 Abs. 2 BGB erforderlichen groben Fahrlässigkeit wird im Allgemeinen ein Handeln verstanden, bei dem die erforderliche Sorgfalt nach den gesamten Umständen in ungewöhnlich großem Maß verletzt worden ist und bei dem dasjenige unbeachtet geblieben ist, was im gegebenen Fall jedem hätte einleuchten müssen. Die diese Definition ausfüllenden inhaltlichen Kriterien entsprechen denen, die im Rahmen des Gutglaubenserwerbs gem. § 932 BGB entwickelt worden sind. Zu berücksichtigen sind danach (vgl. zum Ganzen: OLG Celle, GRUR-RR 2011, 24, Tz. 32 bei juris; Oechsler in: MünchKomm-BGB, 7. Aufl. 2017, § 932 Rn. 48ff.; Lenders in: Herberger/ Martinek/Rüßmann/Weth/Würdinger, jurisPK-BGB, 8. Aufl. 2017, $\S 937$ BGB Rn. 9 f.):

- Art und Gestaltung des Erwerbsgeschäfts wie z. B. die Höhe des Preises (vgl. BGH, Urt. v. 1.7.1987 - VIII ZR 331/86, NJW-RR 1987, 1456, juris Tz. 25) sowie die Veräußerungssituation,

- die Person des Erwerbers wie z. B. dessen geschäftliche oder fachspezifische Erfahrung, an die entsprechend höhere oder niedrigere Anforderungen hinsichtlich seiner Sorgfaltspflicht zu stellen sind,

- die Legitimation des Veräußerers sowie dessen Erklärungen, hinsichtlich derer eine kritische Würdigung des Erwerbers erwartet wird (vgl. BGH, Urt. v. 4.10.1972 - VIII ZR 66/71, MDR 1973, 44, juris Tz. 8),

- sonstige erkennbare Umstände in der Person des Veräußerers, z. B. ob dieser bekannt oder unbekannt in der maßgeblichen Branche ist.

- Die verkehrsübliche Abwicklung des Geschäfts in der betreffenden Branche ist bei der Beurteilung der Erwerbssituation von Bedeutung, wobei allerdings branchen- oder verkehrsübliche Schlampereien oder Leichtsinn keinen Anlass darstellen, die grobe Fahrlässigkeit zu verneinen (vgl. BGH, Urt. v. 17.12.1969 - VIII ZR 35/68, MDR 1970, 410).

- Über diese Kriterien hinaus kann im Einzelfall eine Nachforschungspflicht des Erwerbers hinsichtlich der Eigentumsverhältnisse an dem zu erwerbenden Gegenstand entstehen. Solche Nachprüfungs- und Erkundigungspflichten sind jedenfalls im Falle einer konkreten Verdachtssituation erforderlich, in der sich dann eine Bösgläubigkeit ergibt, wenn der Erwerber einem sich aufdrängenden objektiven Verdacht nicht nachgeht und eine gebotene Aufklärung unterlässt (vgl. BGH, Urt. v. 4.10.1972 - VIII ZR 66/71, MDR 1973, 44, juris Tz. 8; Urt. v. 13.4.1994 - II ZR 196/93, NJW 1994, 2022, juris Tz. 19; OLG Celle, OLGR 2004, 70, juris Tz. 54). Dabei begründen insbesondere verkehrstypische Gefahrensituationen, zu denen die Veräußerung besonders wertvoller Gegenstände, vor allem Kunstgegenstände jeglicher Art, zählt, Rückfragen zu den Eigentumsverhältnissen an der Sache (Oechsler in: MünchKomm-BGB, 7. Aufl. 2017, § 932 Rn. 64 f.). 
[116] Hinsichtlich erst nach Besitzerwerb eingetretener Bösgläubigkeit erfordert das Gesetz positive Kenntnis; grob fahrlässige Unkenntnis genügt insoweit nicht.

[117] Der Besitzer einer Sache hat von den seine Nichtberechtigung zum Besitz begründenden Umständen und damit vom Mangel seines Rechts zum Besitz nicht schon dann positive Kenntnis erlangt, wenn diese Umstände ihm gegenüber lediglich behauptet oder ihm in einer solchen Weise übermittelt werden, dass er berechtigten Anlass hat, an der Richtigkeit dieser Umstände zu zweifeln. Die Kenntnis der Umstände und des sich aus ihnen ergebenden Mangels des Rechts zum Besitz muss aber dann als erlangt gelten, wenn dem Besitzer die Rechte des Eigentümers durch liquide Beweise dargetan oder er über den Mangel seines Besitzrechts in einer Weise aufgeklärt wird, dass sich ein redlich Denkender der Überzeugung hiervon nicht verschließen würde (BGH, Urt. v. 22.1.1958 - V ZR 27/57, BGHZ 26, 256, Tz. 49 bei juris zu § 990 Abs. 1 S. 2 BGB; Kindl in: Bamberger/ Roth, BeckOK-BGB, 41. Edition 2016, § 937 Rn. 6).

[118] 3. Im Rahmen der beschränkten Überprüfbarkeit der Beweiswürdigung in der Berufungsinstanz (siehe oben B IV 3 a) ist die Wertung des LG, nach dem Ergebnis der Beweisaufnahme sei Bösgläubigkeit des Beklagten nicht nachgewiesen, nicht zu beanstanden.

[119] a) Der Umstand der Schenkung an sich und das daraus folgende Fehlen von Erwerbsdokumenten (sei es für das Verhältnis zwischen Beklagtem und dessen Stiefvater, sei es für das Verhältnis zwischen Stiefvater und dessen Besitzvorgänger) rechtfertigen noch nicht den Vorwurf der Fahrlässigkeit. Wer ein Geschenk erhält, handelt insbesondere nicht schuldhaft, wenn er dem Schenker gegenüber die Nachfrage nach entsprechenden Belegen unterlässt; vielmehr wird üblicherweise der Anstand gebieten, bei Erhalt eines Geschenks die Nachfrage nach solchen Dokumenten, aus denen sich regelmäßig auch der Erwerbspreis ergeben wird, zu unterlassen.

[120] b) Soweit die Berufung pauschal behauptet, der Stiefvater habe die Bilder „im Privatkauf durch einen unverhältnismäßig günstigen Preis erworben“, „so gut wie nichts bezahlt und diese „für einen Apfel und ein Ei" bzw. "für ein Butterbrot und ein $\mathrm{Ei}^{\prime \prime}$ gekauft, ist dies durch nichts belegt und war vom Beklagten so auch nicht vorgetragen worden; der Beklagte hatte lediglich angegeben, sein Stiefvater habe ihm gegenüber erwähnt, "dass er die Gemälde in Dinkelsbühl erworben habe und dabei auch einen geringen Wert angenommen habe" (S. 7 der Klageerwiderung vom 7.11.2014 = Bl. 28 d.A.). Auch zur finanziellen Situation des Stiefvaters, eines Fuhrunternehmers für Sand und Schotter, ist nichts vorgetragen. Die vom Kläger mit nachgelassenen Schriftsätzen vom 22.8.2017 und vom 23.8.2017 weiter behaupteten Umstände, dass der Stiefvater des Beklagten sich die Erwerbsquelle der Bilder "noch nicht einmal notiert hat" und dass dieser "kein Kunstinteressent und Kunstsammler war" und ihm weder Signatur noch Malstil des Malers H.P. bekannt gewesen seien, sind gleichfalls nicht belegt.
Im Übrigen wären diese Umstände für die Frage der Bösgläubigkeit des Beklagten irrelevant. Selbst aus einer - unterstellten - Bösgläubigkeit des Stiefvaters des Beklagten bei Erwerb der Bilder würde noch nicht folgen, dass der Beklagte - dem die Erwerbsumstände seines Stiefvaters nicht bekannt sein müssen und nicht zugerechnet werden können - in gleicher Weise bösgläubig wäre.

[121] c) Soweit der Kläger in den vorgenannten nachgelassenen Schriftsätzen als unglaubhaft rügt, "dass auch der Kunsthändler, der angeblich die Bilder dem Stiefvater ... überlassen hat" trotz deren Signatur deren Wert nicht erkannt haben soll und sie entsprechend zu einem geringen Preis an den Stiefvater des Beklagten verkauft haben soll, bedingt dies nicht zwingend die Bösgläubigkeit des Beklagten. Es steht bereits nicht fest, dass der Stiefvater des Beklagten die beiden Gemälde von einem Kunsthändler erwarb und nicht etwa - wie als weitere Möglichkeit vorgetragen - von einem Antiquitätensammler. Auch der (nicht näher dargelegte, pauschal auf Recherchen des Klägers gestützte) Verweis in den nachgelassenen Schriftsätzen auf die Nichtexistenz einer "namhaften Galerie in Dinkelsbühl die Gemälde der klassischen Moderne von dieser Qualität und in diesem Preissegment üblicherweise verkauft" ist deshalb unbehelflich.

[122] Weiter steht auch nicht fest, dass derjenige, der an den Stiefvater des Beklagten die Bilder veräußerte, deren Wert erkannte, was - zumal bei Veräußerung durch einen privaten Antiquitätensammler - nicht zwingend erscheint. Jedenfalls kann der Beklagte hinsichtlich dieser ihm nicht erkennbaren und nicht zurechenbaren Umstände nicht als bösgläubig angesehen werden.

[123] d) Soweit die Berufung darauf abstellt, dass der Beklagte nicht über Kunstverstand und kunsthistorisches Interesse und auch nicht über die finanziellen Mittel zum Erwerb der Bilder verfügt habe, so ist letzteres nicht festgestellt und - im Hinblick auf die behauptete Schenkung - auch nicht relevant. Auch fehlender Kunstverstand lässt die Annahme eines aus zwei Gemälden bestehenden Geschenks des Stiefvaters nicht als grob fahrlässig erscheinen.

[124] e) Es kann auch nicht gesagt werden, dass der Beklagte den Wert der ihm geschenkten Bilder hätte erkennen müssen und insoweit - insbesondere durch Unterlassen diesbezüglicher Nachforschungen - grob fahrlässig handelte. Allein die erkennbare Signierung der Bilder mit dem Namenszug „H. P.“ gebot keine weitergehenden Ermittlungen, zumal der Bekanntheitsgrad des Künstlers P. (anders als beispielsweise bei Dürer, Rembrandt oder Picasso) nicht derart groß ist, dass dieser $\mathrm{Na}$ menszug wie auch der Wert eines Gemäldes des benannten Malers jedermann bekannt sein müsste. Auch die vom Beklagten vorgetragene Äußerung seines Stiefvaters, er habe einen geringen Wert der Bilder angenommen, belegt nicht, dass der Beklagte Gegenteiliges grob fahrlässig nicht erkannt hätte. Im Gegenteil spricht gerade der von der Berufung vorgetragene 
fehlende Kunstverstand des Beklagten dagegen, dass dieser einen hohen Wert der Gemälde hätte erkennen müssen. Eine konkrete Verdachtssituation, die eine Nachforschungspflicht des Beklagten hinsichtlich der Herkunft der Gemälde begründen könnte, bestand jedenfalls im Streitfall nicht. Dabei kann offen bleiben, ob es sich bei den sichergestellten Bildern um die Originale, Kopien oder Fälschungen handelt.

[125] f) Das Aufhängen der Bilder zunächst im Privathaus und sodann in - der Öffentlichkeit zugänglichen - Geschäftsräumen des Beklagten spricht für Gutgläubigkeit, wie das LG zutreffend ausgeführt hat. Soweit der Kläger erstmals in den nachgelassenen Schriftsätzen vom 22.8.2017 und vom 23.8.2017 bestreitet, dass die beiden Gemälde jemals in den Geschäftsräumen des Beklagten aufgehängt waren, ist das diesbezügliche Vorbringen verspätet und deshalb nicht mehr zuzulassen, § 531 Abs. 2 S. 1 Nr. 3 ZPO.

[126] Seitens des Beklagten war bereits in erster Instanz vorgetragen worden, dass die Bilder zunächst im Privathaus des Beklagten und anschließend in den Büroräumen im Betrieb Gunzenhausen des Beklagten aufgehängt waren, bevor sie, als nicht mehr zeitgemäß empfunden, abgehängt worden waren (S. 6 der Klageerwiderung vom 7.11.2014 = Bl. 27 d.A.). Ein anfängliches Aufhängen der Gemälde in den Geschäftsräumen hat auch die Zeugin K. H. bekundet („Es war so, dass die beiden Bilder damals in den Geschäftsräumen meines Vaters hingen...").

[127] Das LG hat im angefochtenen Urteil festgestellt, dass die Bilder "im Anwesen des Beklagten und auch in den Geschäftsräumen aufgehängt wurden" (S. 6 der Urteilsgründe). In der Berufungsbegründung des Klägers wird nicht gerügt, dass diese Feststellung unzutreffend sei.

[128] Das nunmehrige Bestreiten ist deshalb verspätet.

[129] g) Der Versuch im Jahre 2009, eines der Bilder aus finanziellen Gründen im Rahmen einer Auktion zu veräußern, belegt per se noch nicht die Kenntnis eines hohen Wertes. Eine diesbezügliche Recherche war nicht geboten.

[130] h) Auch die im Verlauf des staatsanwaltlichen Ermittlungsverfahrens und des nunmehrigen Zivilprozesses erfolgten widersprüchlichen Einlassungen des Beklagten hinsichtlich des Schicksals der Bilder (etwa hinsichtlich des genauen Zeitpunktes des Erwerbs der Bilder, hinsichtlich der Umstände des Erwerbs oder hinsichtlich einer Weiterschenkung an seine Tochter, die Zeugin K. H.) reichen zum Nachweis der Bösgläubigkeit nicht aus, zumal hierfür - gerade im Hinblick auf den Zeitablauf - Erinnerungsschwächen verantwortlich sein können.

[131] i) Gleiches gilt für die Auffindesituation der Gemälde, die von der Polizei in einem Schrank im oberen Stockwerk des Betriebsgebäudes Gunzenhausen des Beklagten aufgefunden wurden. Nach dem Ergebnis der Beweisaufnahme hat der Zeu- ge .M. H., der durch einen Anruf seiner Schwester, der Zeugin K. H. erfahren hatte, dass die Polizei die Bilder sicherstellen wollte, diese ohne Wissen und Veranlassung des Beklagten in einem Schrank im Obergeschoss verwahrt, um zu verhindern, dass Mitarbeiter, Kunden oder Lieferanten hiervon Kenntnis erlangen und dadurch eine Geschäftsschädigung eintreten könne. Die Zeugin K. H. hat hierzu ausgeführt, dass sie von zuhause aus anlässlich der Durchsuchung der Privaträume ihren „Bruder im Geschäft angerufen und ihn gebeten (habe), die Bilder Weg zustellen, damit es wenn die Polizei kommt diesbezüglich kein Aufhebens gibt. Ich hatte halt die Befürchtung, dass Kunden dies sonst mitbekommen und vielleicht sich Gedanken machen über Steuerprobleme oder ähnliches." Der Zeuge M. H. hat ausgeführt, "dass meine Schwester angerufen hat und mitteilte, dass die Polizei da sei und ich die Bilder nach oben bringen sollte, wobei ich das so verstand, dass die Mitarbeiter, Kunden und auch Lieferanten dies nicht mitbekommen. Das Geschäft sollte rausgehalten werden." Gegen ein - für Bösgläubigkeit des Beklagten sprechendes - bewusstes Verstecken der Bilder spricht auch, dass der Beklagte die durchsuchenden Polizeibeamten deren Suche nach dem ergangenen Durchsuchungsbeschluss des AG Ansbach vom 26.8.2009, BI. 10-11 der beigezogenen Ermittlungsakten, zudem lediglich auf das Gemälde „Bildnis Mathilde Vollmoeller" gerichtet war - bereits bei der Durchsuchung seiner Privaträume darauf hingewiesen hat, dass er zwei mit „P." signierte Bilder besitze, dass diese sich in seinem Betrieb in Gunzenhausen befinden würden und Einverständnis mit einer freiwilligen Herausgabe bestehe (Aussagen der als Zeugen vernommenen Polizeibeamten K.R. und J. S.).

[132] j) Soweit der Kläger in den nachgelassenen Schriftsätzen auf das oben (unter B V 2 und B VI 2) zitierte Urt. des OLG Celle vom 10.7.2003 (OLGR 2004, 70) verweist und den ersten Leitsatz dieses Urteils zitiert, erschließt sich dem Senat die Bedeutung dieses Hinweises nicht. Insbesondere hat der Kläger (entgegen der vom OLG Celle entschiedenen Sachverhaltskonstellation) nicht nachgewiesen, dass es sich bei den klagegegenständlichen Gemälde um vom Maler H. P. stammende Originale handelt (siehe oben B III 1), wohingegen das OLG Celle über Herausgabeansprüche hinsichtlich antiquarischer Originalbücher zu befinden hatte.

[133] k) Bei zusammenfassender Würdigung sämtlicher Gesichtspunkte hält auch der Senat den Nachweis einer Bösgläubigkeit des Beklagten im Sinne des § 937 Abs. 2 BGB für nicht geführt. Von Seiten des beweisbelasteten Klägers wurde der gem. § 937 Abs. 2 BGB vermutete gute Glaube des Beklagten nicht widerlegt.

\section{VII.}

[134] Der Beklagte hat damit im Wege der Ersitzung gem. § 937 Abs. 1 BGB originär Eigentum an den beiden sichergestellten Gemälden erworben. Er ist deshalb gegenüber der Staatsan- 
waltschaft Ansbach berechtigt, vom weiteren Beteiligten im Hinterlegungsverfahren, dem Kläger, im Wege der Widerklage die Bewilligung der Freigabe zu verlangen.

[135] Danach ist die Klage abzuweisen und der Widerklage stattzugeben.

[136] Die Vorschriften des Gesetzes zum Schutz von Kulturgut (Kulturgutschutzgesetz - KGSG) vom 31.7.2016 (BGBI. 2016 Teil I S. 1914) gebieten insoweit keine andere Beurteilung. Zwar mag es sich bei den beiden Gemälden jeweils um Kulturgut im Sinne des $\S 2$ Abs. 1 Nr. 10 KGSG handeln. Es ist aber bereits nicht ersichtlich und auch nicht vorgetragen, dass die streitgegenständlichen Gemälde (soweit es sich überhaupt um Originale handelt) nationales Kulturgut im Sinne des § 6 KGSG darstellen und deshalb den insoweit vorgesehenen Beschränkungen des KGSG unterfallen. Fraglich erscheint auch, ob - insbesondere in Anbetracht der gesetzlich vorgesehenen Wertgrenzen (die für Gemälde bei Ausfuhr in die EU 300.000,00 EUR, bei Ausfuhr aus dem EU-Binnenmarkt 150.000,00 EUR betragen) - Ausfuhrbeschränkungen eingreifen (vgl. §§ 20, 21 Nr. 2, 24 Abs. 1, Abs. 2 S. 1 Nr. 1 KGSG, Verordnung (EG) Nr. 116/2009 des Rates vom 18.12.2008 über die Ausfuhr von Kulturgütern, ABI. L 39 vom 10.2.2009, S. 1). Das Verbot des Inverkehrbringens abhandengekommenen Kulturguts ( $\$ 40$ KSGS) würde zudem den - im Streitfall nicht geführten - Nachweis eines Abhandenkommens bedingen.

[137] Jedenfalls stehen die Bestimmungen des KGSG einem Eigentumserwerb infolge Ersitzung gem. § 937 BGB nicht entgegen, selbst wenn das Verbot des Inverkehrbringens gem. § 40 KGSG auch für ersessene Kulturgüter gelten sollte.

\section{VIII.}

[138] Dem Antrag des Klägers in dessen nachgelassenen Schriftsätzen auf Wiedereröffnung der mündlichen Verhandlung ist nicht nachzukommen. Das in diesen Schriftsätzen enthaltene Vorbringen zu den in der mündlichen Verhandlung vom 26.7.2017 erteilten rechtlichen Hinweisen des Senats wurde berücksichtigt, veranlasst indes - wie ausgeführt - keine andere Beurteilung. Das erstmalige Bestreiten des Aufhängens der beiden Gemälde in den Geschäftsräumen des Beklagten hingegen ist bereits von der nachgelassenen Schriftsatzfrist nicht gedeckt und - wie ebenfalls ausgeführt - als verspätet nicht zu berücksichtigen.

[139] Die Voraussetzungen einer Wiedereröffnung der Verhandlung gem. § 156 Abs. 2 ZPO liegen nicht vor. Der Senat hält zudem nach seinem Ermessen eine Wiedereröffnung nicht für angezeigt, § 156 Abs. 1 ZPO.

[140] C. 1. Die Kostenentscheidung folgt aus § 97 Abs. 1 ZPO.

[141] Die Entscheidung zur vorläufigen Vollstreckbarkeit beruht auf §§ $708 \mathrm{Nr}$. 10, 711 ZPO.
[142] 2. Die Revision war nicht zuzulassen, da die Voraussetzungen des § 543 Abs. 2 S. 1 ZPO nicht vorliegen.

[143] Die Rechtssache hat keine grundsätzliche Bedeutung. Eine solche wäre lediglich dann anzunehmen, wenn die Rechtssache eine entscheidungserhebliche, klärungsbedürftige und klärungsfähige Rechtsfrage aufwerfen würde, die über den Einzelfall hinaus Bedeutung für die Allgemeinheit hat. Dies ist nicht der Fall. Die bislang höchstrichterlich nicht entschiedene Frage der Beweislast für die Gutgläubigkeit im Rahmen der Ersitzung bei abhanden gekommenen Sachen ist im Streitfall nicht entscheidungserheblich.

[144] Die Fortbildung des Rechts erfordert keine höchstrichterliche Entscheidung. Auch zur Sicherung einer einheitlichen Rechtsprechung ist eine Entscheidung des Revisionsgerichts nicht geboten; widersprüchliche Entscheidungen zu entscheidungserheblichen maßgeblichen Rechtsfragen liegen nicht vor.

[145] 3. Die Streitwertfestsetzung beruht auf $\S 48$ Abs. 1 S. 1 GKG, § 6 ZPO. Der Streitwert einer Klage auf Bewilligung der Freigabe einer hinterlegten Sache bestimmt sich nach deren Wert (KG, AnwBI 1978, 107). Da Klage und Widerklage hierbei denselben Gegenstand betreffen, sind deren Werte nicht zusammenzurechnen, § 45 Abs. 1 S. 1 und 3 GKG. Die strgg. Gemälde sollen nach Vortrag des Klägers einen Wert von über 100.000,00 EUR aufweisen. 